\title{
Persistence following intermittent punishment and continuous reinforcement: Between and within subjects
}

\author{
PATRICK E. CAMPBELL \\ Wright State University, Dayton, Ohio 45431 \\ and \\ CHARLES T. CLEVELAND \\ Southern Methodist University, Dallas, Texas 75275
}

\begin{abstract}
Rats were given continuous reinforcement in both alleys of a two-alley runway apparatus. For three groups intermittent punishment occurred in one of the alleys ( $P$ alley) but not in the other alley (C alley). A fourth group did not receive punishment but was given control shocks following each daily session. The three punished groups had punished trials followed by rewarded trials in the $\mathrm{P}$ alley, the $\mathrm{C}$ alley, or in both alleys. The persistence of the animals was measured in both alleys with reward and punishment present on every trial. All of the punished animals ran more slowly in the $P$ alley during acquisition and continued this behavior during the continuous punishment testing phase. All of the punished animals ran more rapidly during the test phase than the animals given only control shocks during testing.
\end{abstract}

Early research demonstrated that intermittent punishment superimposed on consistently reinforced (CRF) instrumental responding can lead to greater persistence than schedules not involving contingent shocks (Banks, 1966; Brown \& Wagner, 1964). In these studies the test schedule involved both continuous reinforcement and continuous punishment. Both the Banks and the Brown and Wagner studies suggested that the addition of punishment to a rewarded trial was functionally similar to the occurrence of a nonrewarded trial in a partial reinforcement (PR) schedule. As a result, intermittent punishment superimposed on a CRF schedule resulted in increased persistence in a manner analogous to the partial reinforcement extinction effect (PREE).

Little recent attention has been devoted to the original Brown and Wagner (1964) paradigm involving intermittent punishment and CRF schedules. The purpose of the present study was to investigate their paradigm within the context of sequential trial theory. The design for the present study was drawn from a PR experiment reported by Mellgren and Dyck (1972). In their study animals were trained on a PR schedule in one alley and a CRF schedule in a separate alley. Extinction trials were given in both alleys. Since the occurrence of nonreward $(N)$ to reward $(R)$ transitions is necessary for the development of persistence in this situation, the experimental manipulation involved the location of the

Requests for reprints should be sent to Patrick E. Campbell, Department of Psychology, Wright State University, Dayton, Ohio 45431. Charles Cleveland is now at the Harris County Juvenile Probation Department, Houston, Texas.
N-R transitions. According to sequential theory (Capaldi, 1967), persistence is increased by N-R transitions because these transitions result in the conditioning of the instrumental response to the aftereffect of nonreward. When this conditioning occurs only in the PR alley, rats are expected to show relatively good persistence in that alley, that is, a within-subject PREE. When $\mathrm{N}-\mathrm{R}$ transitions occur in only the CRF alley, rats are expected to persist longer in that alley, that is, a reverse PREE. Finally, when N-R transitions are allowed in both alleys, relatively good persistence in both alleys is expected, that is, a generalized PREE. The Mellgren and Dyck (1972) results supported these expectations in detail. In the present study we simply substituted punished reward for nonreward and repeated the Mellgren and Dyck design.

\section{METHOD}

The subjects were 24 experimentally naive female albino rats of the Sprague-Dawley strain. The rats were approximately 110 days old at the beginning of training.

A straight alley with two parallel runways was used during training. The runways were $182 \times 9 \times 15 \mathrm{~cm}$ with a grid floor (.3-cm grids spaced $1.3 \mathrm{~cm}$ apart). The gray alley had cardboard fillers along the sides, painted solid gray, and the striped alley had cardboard fillers along the sides, painted with alternating black and white vertical stripes. The alleys were covered with clear plastic tops. Start, run, and goal times were measured photoelectrically over 25-, 100-, and 26-cm sections of the alley. A Grason-Stadler Model E 1064 constant-current shock source was wired to the grid floor in the goalbox. Shock could be applied $1.0 \mathrm{sec}$ after the rat made contact with the food in the goal cup, for a duration of $.1 \mathrm{sec}$. The level of current could be adjusted 
at any time. A white masking noise (80-85 dB) was used throughout the experiment.

Before the experiment, all rats were maintained on aa-1lv food and water. Prior to training, each rat was reduced to $85 \%$ of its free-feeding body weight. All rats were maintained at $85 \%$ body weight throughout the experiment by one make-up feeding per day given at least $15 \mathrm{~min}$ after the day's trials.

On the first day of pretraining each rat was placed to reward for two 5-min sessions in a black pretrainer closely resembling the goalbox. Rats were also given free access to each alley for $5 \mathrm{~min}$ in pairs, following which they were placed individually in each goalbox with the reward. The reward throughout the experiment consisted of 4 Noyes $97-\mathrm{mg}$ food pellets. Days 2, 3, and 4 of pretraining were different from Day 1 only in that each rat explored the runways individually and for progressively shorter lengths of time. On Days 5 and 6 of pretraining each rat received one rewarded trial in each alley.

During the 12 days of acquisition all 24 rats received four trials a day in each alley. Reward was present on all trials. Rats in the three punished groups were punished on two of the eight trials. Punishment was administered only in the $P$ alley (either gray or striped in a counterbalanced manner). One group (SP-P) had punished trials followed by rewarded trials in the $P$ alley. A second group ( $\left.\mathrm{S}^{\mathrm{P}}-\mathrm{C}\right)$ had punished trials followed by rewarded trials in the C alley. A third group (SP-PC) had $50 \%$ of the punished trials followed by rewarded trials in the $P$ alley and the other $50 \%$ of the punished trials followed by rewarded trials in the $\mathrm{C}$ alley. The fourth group (CRF) never received punishment during trials. Approximately $10 \mathrm{~min}$ after their last daily trial, the CRF animals received two placements in a black goalbox and were given one shock at each placement. The duration of time between placements was $20 \mathrm{sec}$. The shock intensity was gradually increased from $.1 \mathrm{~mA}$ to $.5 \mathrm{~mA}$ during the 12 training days for all animals. The duration remained constant at $.1 \mathrm{sec}$ and the delay remained constant at $1.0 \mathrm{sec}$. The rats were left in the goalbox until they finished eating. If the rat had not automatically tripped the shock mechanism by making contact with the food in the goal cup within $5.0 \mathrm{sec}$ after entering the goalbox, then shock was administered manually.

Four different sequences of gray and striped alleys were used, with each sequence being used three times. On any given day all rats received the same sequence of gray and striped alleys. The sequences were the same as those used by Mellgren and Dyck (1972), except that punishment was used instead of nonreward.

After acquisition was completed, the rats were given 2 days of continuous punishment testing. Each rat received 16 trials each day, with both reward and punishment present on every trial. The sequence of gray (G) and striped (S) alleys, derived from Mellgren and Dyck (1972), was as follows: Day 1, G S S G S S G G S S G G S G G S; Day 2, G G S S S G G S S S G G S S $\mathrm{G}$. The rats were allowed a maximum of $30 \mathrm{sec}$ in each section of the runway. If a rat failed to traverse a section of the runway within $30 \mathrm{sec}$, the experimenter moved it to the next section. During this continuous punishment testing phase, the intensity of the shock was $.5 \mathrm{~mA}$. The duration, delay, intertrial interval, and the maximum time to consume reward remained the same as during acquisition.

\section{RESULTS}

The response times were converted to a speed measure (centimeters/second) and averaged over blocks of trials. Since the sectional results were quite similar, only the results of the total alley measure will be presented here.

Figure 1 presents the acquisition data for each of the four schedules in blocks of eight trials. Inspection of the figure suggests a clear separation between the punished

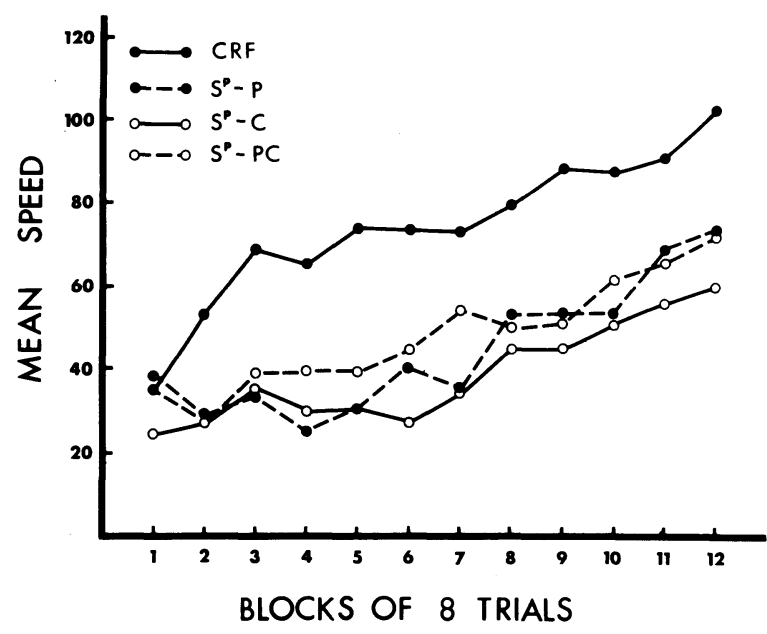

Figure 1. Mean total alley speeds in blocks of eight acquisition trials.

groups, on the one hand, and the noncontingently shocked control animals on the other. An analysis of variance confirmed this suggestion. Groups proved to be significant as a main effect $(F=3.69, \mathrm{df}=3 / 16, \mathrm{p}<.05)$, and an HSD constrast procedure showed that the only significant $(p<.05)$ difference among the groups involved contrasts between the CRF animals and each punished group. In addition, all of the punished groups ran more slowly in the $\mathrm{P}$ alley than in the $\mathrm{C}$ alley (data not shown).

The continuous punishment test phase data were converted to speeds, as in acquisition, and, again, only the total alley measure will be presented. Figure 2 shows each day of the test phase data for each group in blocks of two trials. The data are plotted separately for trials run in the previously shocked alley ( $\mathrm{P}$ alley) and the previously nonshocked alley ( $\mathrm{C}$ alley). Of course, all test trials involved shock; the $\mathrm{P}$ - or $\mathrm{C}$-alley designation refers to the schedule of punishment during acquisition.

An inspection of the upper panel of Figure 2 shows rather clearly that all three of the groups that were punished during acquisition ran somewhat slower in the $\mathrm{P}$ alley than in the $\mathrm{C}$ alley. On the other hand, the animals that received only noncontingent shock (CRF) ran somewhat slower overall and did not differentiate between the two alleys. An analysis of variance clearly supported this observation, with a highly significant interaction of Group by Alley Type $(F=11.15$, df $=3 / 16, p<.05)$. In addition, simple main effects showed $(p<.05)$ that each of the punished groups ran significantly faster in the $\mathrm{C}$ alley, but the CRF animals failed to show this pattern $(p>.05)$. The lower panel of Figure 2 shows these same comparisons for the second day of the test phase. These data appear quite similar to the data from the first day. The Groups by Alley Type interaction was again significant $(\mathrm{F}=9.71, \mathrm{df}=3 / 16$, $\mathrm{p}<.05$ ), but the simple main effects were significant only for the SP-PC and SP.P groups. Unlike the first 

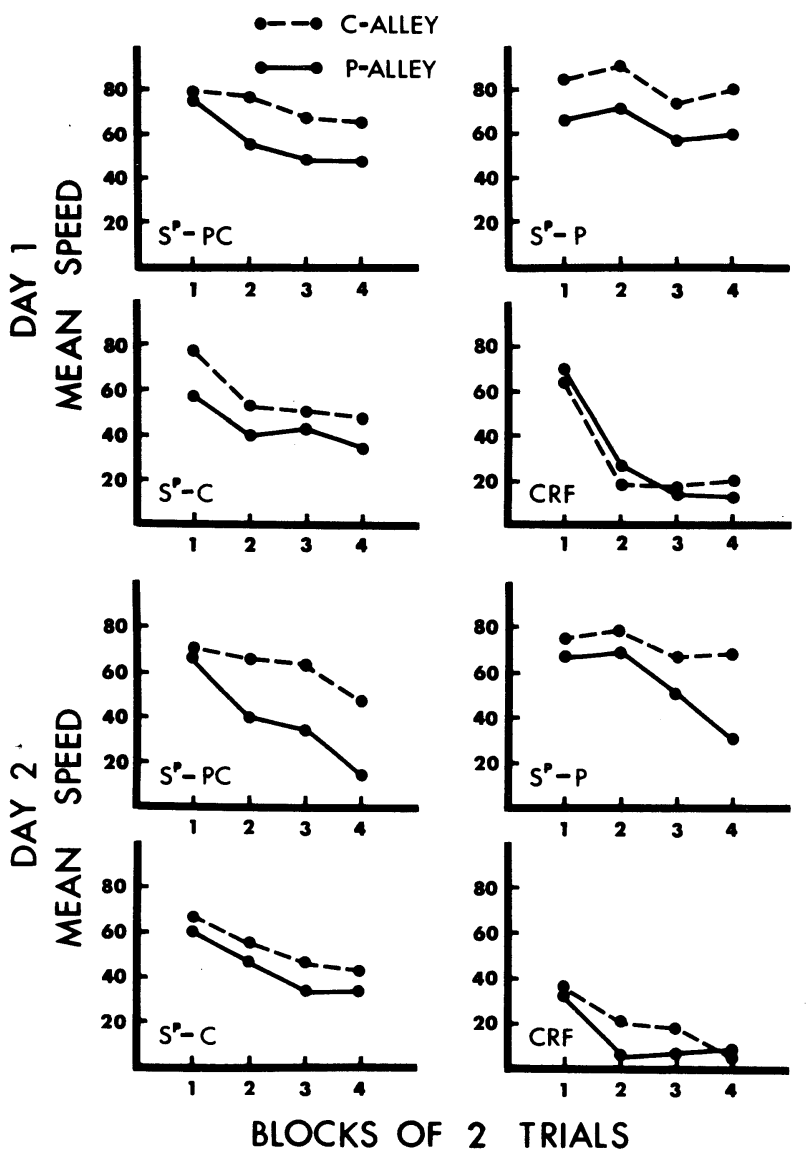

Figure 2. Mean total alley speeds in each alley for each day of the continuous punishment phase.

day, the $\mathrm{SP}_{-} \mathrm{C}$ group did not result in a significant simple main effect.

Figure 3 shows the results for each test day in a way that facilitates the inspection of differences among the groups irrespective of the alley involved. In other words, Figure 3 shows between-subjects comparison, while Figure 2 emphasizes within-subject comparison. Shown in this way, the test data clearly suggest a rather large

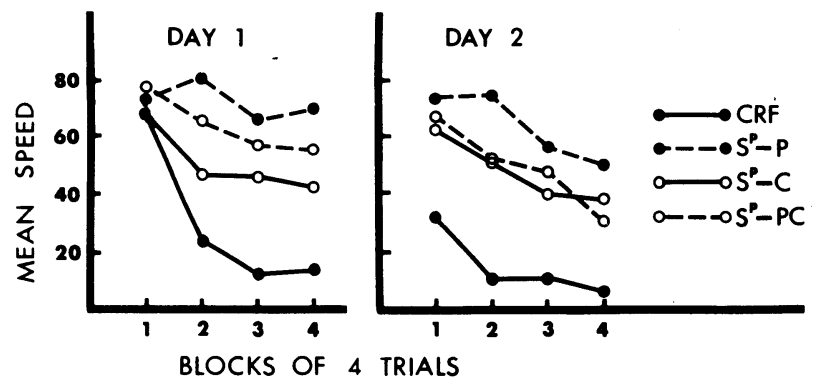

Figure 3. Mean total alley speeds for between-subjects comparisons for each day of the continuous punishment phase. between-subjects partial punishment effect. An analysis of variance revealed significant Groups effects for both Day $1(\mathrm{~F}=5.66, \mathrm{df}=3 / 16, \mathrm{p}<.05)$ and Day 2 $(F=5.70, \mathrm{df}=3 / 16, \mathrm{p}<.05)$. The results of HSD contrasts showed that the CRF animals ran slower than the punished groups during each day. In addition, the contrast between the SP-P and SP-C groups reached significance $(p<.05)$ during the first day of testing.

\section{DISCUSSION}

The acquisition results clearly indicated that our shock intensity clearly qualified as a punishing stimulus. All of the punished groups ran more slowly than the animals given only control shocks. In addition, the punished animals ran more slowly in the $\mathrm{P}$ alley than in the $\mathrm{C}$ alley, indicating the development of a discrimination.

The results of the continuous punishment test phase did not show the development of a within-subjects partial punishment effect (PPE) in any of the punished groups. Instead, all of the punished animals ran faster in the $C$ alley than in the $P$ alley, demonstrating a reversed PPE. It is obvious that the intermittent punishment situation used here is not simply a punishment analog of the partial reinforcement situation used by Mellgren and Dyck (1972).

One possible explanation for the discrepancy between our data and those of Mellgren and Dyck is that our animals clearly preferred the $\mathrm{C}$ alley during acquisition and developed a pronounced tendency to run more rapidly in that alley than in the $P$ alley. In order to show a within-subjects PPE, our animals needed to reverse a pattern of behavior that was developed during the acquisition phase. The animals in the Mellgren and Dyck (1972) study did not develop an analogous preference for the $\mathrm{C}$ alley in their partial reinforcement investigation.

When between-subjects comparisons are considered, the present results show a rather robust PPE for all of the punished groups. In addition, there was some evidence that the animals receiving $\mathrm{P}-\mathrm{R}$ transitions in the $\mathrm{P}$ alley developed a stronger PPE than the other punished animals. Since this finding was neither expected nor of large magnitude, we do not intend to offer an explanation at this time.

\section{REFERENCES}

Banks, R. K. Persistence to continuous punishment following intermittent punishment training. Journal of Experimental Psychology, 1966, 71, 373-377.

Brown, R. T., \& WAgNeR, A. R. Resistance to punishment and extinction following training with shock or nonreinforcement. Journal of Experimental Psychology, 1964, 68, 503-507.

CAPALDI, E. J. A sequential hypothesis of instrumental learning. In K. W. Spence \& J. T. Spence (Eds.), The psychology of learning and motivation (Vol. 1). New York: Academic Press, 1967. Pp. 67-156.

Mellgren, R. L., \& Dyck, D. G. Partial reinforcement effect, reverse partial reinforcement effect, and generalized partial reinforcement effect within subjects. Journal of Experimental Psychology, 1972, 92, 339-350.

(Received for publication October 13, 1976.) 